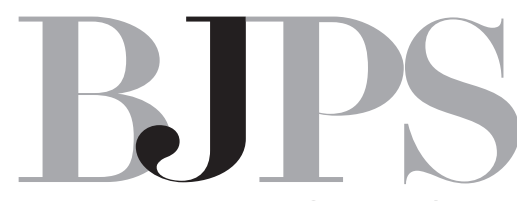

Brazilian Journal of

\title{
Internationalizing Brazilian Pharmaceutical Sciences
}

Internationalization is the watchword today! Every single university, research institutes and areas of science are going for it. To be part of the globalized world is the main goal for every institution all over the planet in the $21^{\text {st }}$ century. Although the effort started at the end of the last century, it grew stronger in the New Millennium.

What is the importance of being more and more international? In the scope of Higher Education Institutions it means to upgrade human resources with higher quality, both among undergraduate and graduate students, and also to allow faculty, staff and researchers to update towards better expertise and qualification. Besides, sharing cultural diversity represents not only professional but also personal experience, which contributes to turn a person into a better human being.

In this point of view, it is also important to look for the internationalization of the science we have been developing. In Brazil, Pharmaceutical Sciences comprehend not only Drugs and Medicines as in most countries all over the world, but also Food and Experimental Nutrition, and Clinical and Toxicological Analysis. It is important to think about how those areas are being developed in other countries and to compare our indicators with world parameters.

SCImago Journal and Country Rank (www.scimagojr.com) is a portal that contains journals and scientific indicators from Scopus data base. The indicators have been used to analyze the scientific scenario of the countries compared with each other and with those in selected regions worldwide. Publications involving international collaboration can reflect the level of internationalization of a determined scientific area.

Concerning Pharmaceutical Sciences in Brazil, SCImago indicators point to an increment in international collaboration from around $15 \%$ in 1996 to about $17 \%$ in 2012, with fluctuations along the period. A maximum value of $26 \%$ was observed in 2008 and a minimum, around 5\%, in 2000. It is possible to observe that Brazil meets the same pattern as that in Latin America, whose percentage of international collaboration was approximately $22 \%$ in 2012 . This means that Brazil contributes significantly to the international collaboration in this continent. It is worth noting that the highest differences concerning international collaboration were observed between our country and Western Europe. 


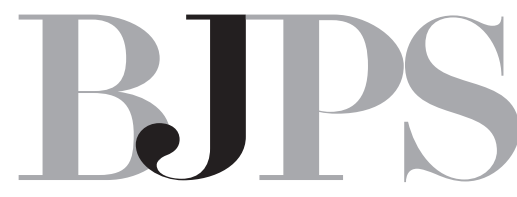

Brazilian Journal of Pharmaceutical Sciences

BRAZILIAN JOURNAL OF

PHARMACEUTICAL SCIENCES

Those features of Brazilian Pharmaceutical Sciences lead us to search for increasing significantly the insertion of this area worldwide. This depends on the quality of research we have been developing, so as to increase the opportunities of international collaboration. And increasing the international collaboration will increase the quality of our research, in a virtuous cycle.

So, let us do our best to make Brazilian Pharmaceutical Sciences recognized worldwide!

Elizabeth Igne Ferreira

Scientific Editor 